\title{
A coleta seletiva nas pesquisas brasileiras: uma avaliação metodológica
}

\author{
Selective waste collection in Brazil: comparing reports and research \\ methodologies
}

Leonardo Silveira Conke $^{[0]}$, Elimar Pinheiro do Nascimento ${ }^{[b]}$

[a] Universidade de Brasília (UnB), Departamento de Administração, Brasília, DF, Brasil

${ }^{[b]}$ Universidade de Brasília (UnB), Centro de Desenvolvimento Sustentável, Brasília, DF, Brasil

\section{Resumo}

A coleta seletiva é uma atividade que tem atraído grande interesse da sociedade, tanto pela sua contribuição à sustentabilidade urbana como pela geração de renda, de cidadania e pela economia de recursos naturais que proporciona. A melhoria na prestação desse serviço depende de uma avaliação adequada da sua situação, algo normalmente realizado por meio de levantamentos estatísticos. Contudo, ao se analisar as quatro principais pesquisas brasileiras sobre o tema, descobriu-se que elas apresentam dados bastante contrastantes. Um dos mais divergentes refere-se ao número de municípios que oferecem a coleta seletiva que, segundo os relatórios, pode ser de $14 \%, 20 \%, 32 \%$ ou $60 \%$. Por isso, buscou-se aqui comparar os procedimentos metodológicos adotados nas pesquisas brasileiras sobre coleta seletiva, a fim de explicar suas divergências e esboçar um panorama da oferta desse serviço no país. Os resultados revelaram que a coleta seletiva ainda é incipiente em abrangência (ocorre em apenas $41 \%$ dos municípios) e em eficiência (apenas 10\% daquilo que é potencialmente reciclável é recolhido). Descobriu-se também que há espaço para aperfeiçoamento na produção dos relatórios, especialmente nos métodos amostrais, nas técnicas estatísticas para os cálculos finais e na qualidade das perguntas dos questionários, fatores que mais influenciaram as disparidades observadas.

Palavras-chave: Coleta seletiva. Sustentabilidade urbana. Resíduos sólidos.

\section{Abstract}

Selective waste collection is an activity recognized for its role in urban sustainability. This is especially true in Brazil, where it generates wealth, employment and social inclusion. However, a better understanding of this public service depends on the proper evaluation of its situation. While analyzing the main national reports on selective waste collection, we observed some contrasting statistics. One that deserves attention is the percentage of cities that offer such programs, with values of $14 \%, 20 \%, 32 \%$ and $60 \%$ found in the reports. Therefore, the purpose here was to compare the methods used in these reports in order to find explanation for these differences.

LSC é doutor em Desenvolvimento Sustentável, e-mail: leonardoconke@unb.br EPN é doutor em Sociologia, e-mail: elimarcds@gmail.com 
The results showed that the sampling method, the quality of the questions, and statistical techniques used in the analyses were responsible for the major variations. Furthermore, it was found that selective waste collection is still incipient in Brazil because recycling programs are available in just $41 \%$ of the cities and only about $10 \%$ of potentially recyclable waste is actually collected.

Keywords: Selective waste collection. Urban sustainability. Solid waste.

\section{Introdução}

Quando se trata de sustentabilidade urbana, um dos maiores desafios enfrentados pelos municípios brasileiros é a gestão dos resíduos sólidos. Desde os anos 1990, com o aumento do consumo das famílias, a questão dos resíduos sólidos tem ganhado notoriedade no Brasil: o lixo é visto como um problema ambiental por $28 \%$ dos brasileiros e como o principal problema ambiental urbano por $47 \%$ (Brasil, 2012). Mais do que os perigos sanitários e de saúde pública resultantes do acúmulo do lixo, existe a preocupação com a preservação do ambiente natural e com a reutilização de recursos. Isso obrigou as administrações municipais a prestarem maior atenção ao gerenciamento desses resíduos, processo que envolve o controle sobre o seu recolhimento, transporte, tratamento e destinação final.

Uma das opções que tem se destacado para o reaproveitamento adequado de recursos é a coleta seletiva. De fato, a Política Nacional de Resíduos Sólidos (PNRS) reconheceu o resíduo sólido reutilizável e reciclável como um bem econômico e de valor social, gerador de trabalho, renda e cidadania (Brasil, 2010). Essa noção tem incentivado a implantação de novos programas municipais de coleta seletiva que, quando bem administrados, podem diminuir o impacto ambiental de lixões e aterros, melhorar a paisagem urbana e aumentar a inclusão socioprodutiva (Grimberg \& Blauth, 1998).

0 aprimoramento na prestação de um serviço público como a coleta seletiva depende, primeiramente, da correta avaliação de como ele é oferecido no espaço urbano. Administradores municipais, entidades públicas, associações e outras instituições interessadas costumam produzir levantamentos com dados qualitativos e quantitativos sobre serviços dessa natureza, que servem de base para a avaliação de quais atividades e regiões que necessitam de maiores investimentos. No caso da coleta seletiva, mais especificamente, as pesquisas nacionais trazem dados incompatíveis: de acordo com os principais relatórios do país, a quantidade de municípios que possuem programas de coleta seletiva é de $14 \%, 20 \%, 32 \%$ e $60 \%$, números respectivamente apontados por CEMPRE (2012), SNIS (Brasil, 2014), IBGE (2012) e ABRELPE (2012). A existência de valores tão divergentes pode ocasionar uma percepção distorcida da realidade, influenciando inclusive, as decisões sobre a implantação e/ou reforço dos programas.

Desse modo, buscou-se aqui comparar as pesquisas brasileiras sobre coleta seletiva para esclarecer as origens dos resultados contrastantes e identificar os espaços de aprimoramento na sistematização das informações sobre esse serviço. Adicionalmente, descrevemos, a partir dos dados numéricos obtidos, um panorama da oferta da coleta seletiva no Brasil.

\section{Referencial teórico}

A primeira experiência brasileira de coleta seletiva (infelizmente não registrada) ocorreu em São Paulo, na década de 1960. Em 1978, tentativa semelhante aconteceu em Porto Alegre (RS) e, em 1985, nos municípios de Niterói (RJ) e Pindamonhangaba (SP) (Brasil, 1985).

Muito associada à separação e à reciclagem, a coleta seletiva não é apenas um recolhimento diferenciado do lixo e sim um ciclo que se inicia com a geração e descarte do resíduo e se completa com o material reciclável sendo reempregado em um processo produtivo (Grimberg \& Blauth, 1998; IBAM, 2001). 0 processo (Figura 1) é iniciado após o consumo domiciliar de algum produto ou serviço cujos resíduos gerados são dispostos na frente das casas, nos logradouros públicos ou em Pontos de Entrega Voluntária (PEVs). Alguns domicílios podem pré-selecionar os resíduos e os acondicionar de forma a garantir a integridade dos materiais potencialmente aproveitáveis. A etapa seguinte é a coleta propriamente dita: na modalidade regular, veículos coletores municipais ou de empresas terceirizadas transportam o lixo ao seu local de 


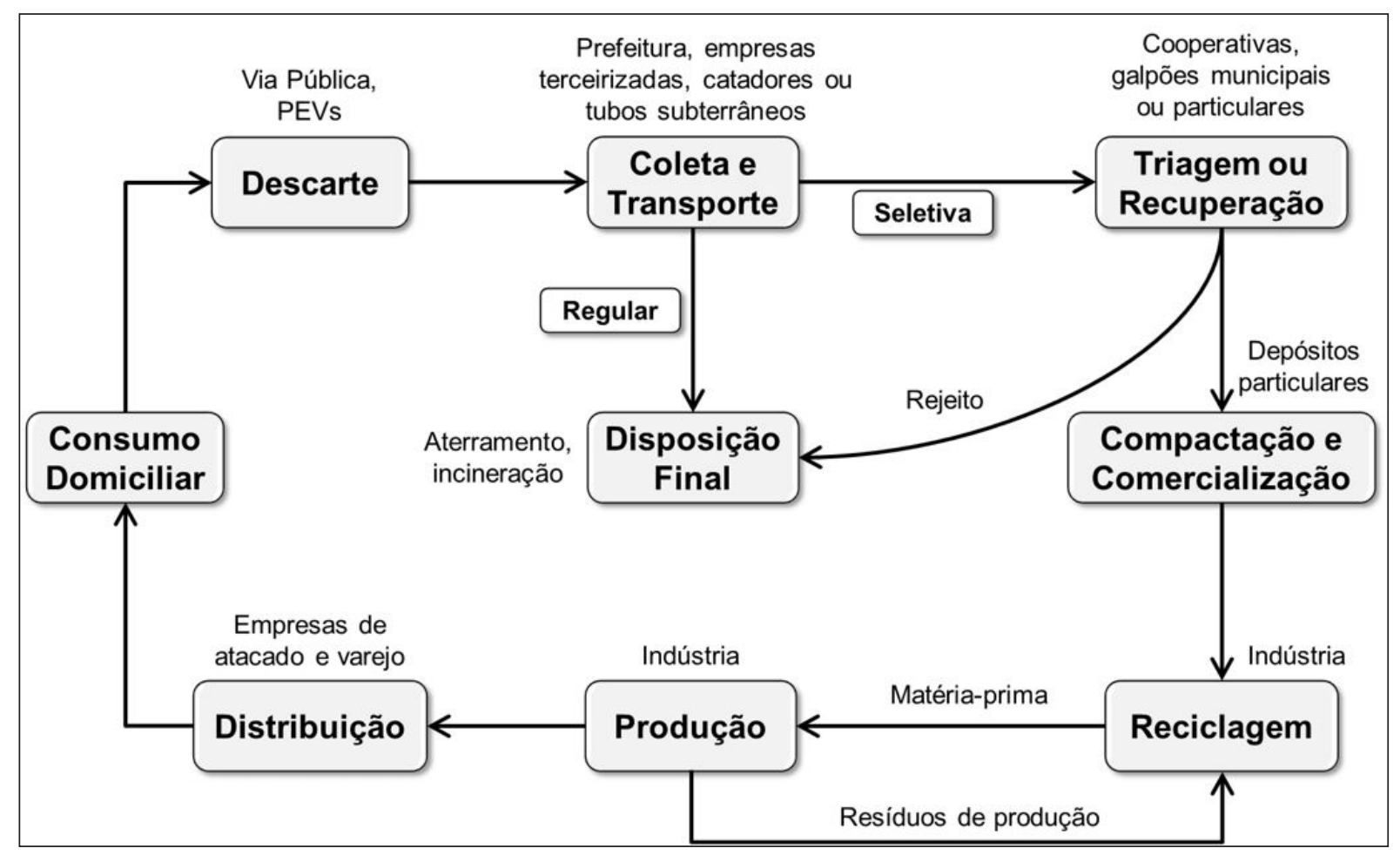

Figura 1 - Ciclo da coleta de lixo domiciliar urbana ${ }^{1}$

Fonte: Elaborado pelos autores com base em Tchobanoglous \& Kreith (2002), IBAM (2001) e Grimberg \& Blauth (1998).

disposição final (aterro sanitário, usina de incineração, lixão etc.), terminando assim o ciclo; na seletiva, a coleta pode ser feita porta a porta (quando os veículos coletores oficiais ou catadores recolhem os resíduos deixados nos logradouros públicos) ou por meio dos PEVs (caçambas, contêineres ou lixeiras de fácil acesso nas quais os cidadãos entregam materiais recicláveis ou os trocam por alimentos, material de construção, material escolar, descontos para eventos culturais etc.) (Cempre, 2010; IBGE, 2010; Tchobanoglous \& Kreith, 2002). Um terceiro método, raro no Brasil, ocorre por meio de um sistema subterrâneo: os resíduos são depositados em recipientes localizados abaixo do solo e transferidos até as centrais de triagem por caminhões com guindaste ou por tubulações (Kaliampakos \& Benardos, 2013).

0 material recolhido na coleta seletiva é então destinado ao tratamento: a porção orgânica dos resíduos pode ser aproveitada pela compostagem, processo que pode gerar adubos de uso doméstico, agrícola ou na jardinagem; os recicláveis secos seguem para a

\footnotetext{
${ }^{1} \mathrm{O}$ ciclo apresentado é genérico. Entende-se que ele pode ser distinto em cada município, o qual acaba desenvolvendo um fluxo mais compatível com as suas características.
}

triagem (ou recuperação), uma espécie de separação qualificada que ocorre em usinas administradas pelo órgão municipal ou por cooperativas e associações de catadores (Grimberg \& Blauth, 1998). A separação nessas unidades difere bastante daquela realizada em domicílios, já que ela é feita com base no potencial reciclável e comercial de cada um dos vários subtipos de material (papel, papelão, plástico, vidro e metais). Após a recuperação, a porção de material que não pode ser transformada, está em mau estado ou não tem valor de mercado é considerada rejeito e é levada aos aterros sanitários ou outros locais de disposição final; já os recicláveis são vendidos a depósitos e comerciantes, que os compactam em grandes volumes e os revendem às indústrias recicladoras. Essas transformam o que foi recebido em insumos, reinserindo o material no ciclo produtivo.

Deve-se ressaltar que, tecnicamente, a reciclagem significa um conjunto de operações industriais que modificam as características físicas de determinado material para aprimorar suas propriedades, seu rendimento e para que possa ser transformado em outro produto (Penteado, 2011; Grimberg \& Blauth, 1998). Ele pode ser pré-consumo (referente 
às sobras de produção e aos resíduos gerados na fabricação de bens) ou pós-consumo (como na coleta seletiva, que envolve materiais que já passaram pelos consumidores finais e que não podem ser aproveitados para o objetivo inicialmente proposto) (ISO, 1999). Penteado (2011) adverte, no entanto, que a ideia de reciclável não está associada somente à existência de tecnologia de transformação física dos materiais, mas principalmente à sua viabilidade de comercialização; itens sem valor no mercado são considerados rejeitos (não recicláveis). De qualquer forma, juntamente com o reparo, o recondicionamento e a remanufatura, a reciclagem é uma das formas de se reaproveitar parte daquilo que foi descartado no ciclo produtivo (King et al., 2006).

Por fim, lembra-se a existência de um ator bastante participativo na coleta seletiva mas que não está representado no processo: as prefeituras, governos ou os departamentos a eles vinculados. A sua atuação é mais visível quando detêm a propriedade de caminhões, máquinas e equipamentos e quando efetivamente realizam operações de coleta. Nos casos em que há concessão ou terceirização das atividades, eles ficam responsáveis pelo gerenciamento do sistema, mediando a relação entre os atores, fornecendo infraestrutura, fiscalizando as operações, criando regulamentação e políticas públicas pertinentes e promovendo ações de sensibilização (IBAM, 2001).

\section{Métodos}

Os quatro relatórios analisados foram selecionados intencionalmente devido a sua ampla aceitação e por terem sido desenvolvidos por organizações que desfrutam de certa credibilidade. A principal razão, entretanto, foi o fato de elas declararem que suas pesquisas possuem abrangência nacional. Como os relatórios são as fontes primárias de dados, torna-se necessária uma breve explicação sobre eles e sobre as instituições que os produziram.

O Instituto Brasileiro de Geografia e Estatística (IBGE) é uma entidade da administração pública federal que produz, analisa e divulga estatísticas sobre temas sociais, econômicos, demográficos e geográficos do território brasileiro. Teve seu início em 1871, como Diretoria Geral de Estatística, mas só adquiriu seu nome atual em 1937, quando o Conselho Nacional de Geografia foi incorporado ao Instituto Nacional de Estatística. Seus dois estudos com dados primários sobre a coleta seletiva são a Pesquisa Nacional de Saneamento Básico (PNSB) e a Perfil dos Municípios Brasileiros (MUNIC). Essa última é focada na gestão municipal e avalia alternadamente áreas como estrutura, dinâmica e funcionamento das instituições públicas. Realizada anualmente desde 1999, a MUNIC foi preferida à PNSB por apresentar um conjunto mais completo e adequado de dados (IBGE, 2014).

Também vinculado ao governo federal, mais especificamente ao Ministério das Cidades, o Sistema Nacional de Informações sobre Saneamento (SNIS) é um banco de dados criado em 1996 sobre as operações, a gestão, as finanças e a qualidade dos serviços de água, esgoto e de destinação de resíduos sólidos dos municípios brasileiros. É no Diagnóstico do Manejo de Resíduos Sólidos Urbanos que a coleta seletiva é anualmente avaliada e, por isso, ele foi o selecionado para a análise (Brasil, 2014).

As duas outras pesquisas derivam de organizações privadas e sem fins lucrativos. O Compromisso Empresarial para a Reciclagem (CEMPRE) é uma associação cujo objetivo é promover a reciclagem, a redução e a reutilização do lixo por meio de manuais, guias técnicos e seminários. Criada em 1992, um dos seus mais conhecidos trabalhos é o CICLOSOFT, levantamento bianual iniciado em 1994 e dedicado exclusivamente à coleta seletiva (CEMPRE, 2012). Por fim, a Associação Brasileira de Empresas de Limpeza Pública e Resíduos Especiais (ABRELPE) realiza estudos e outras atividades para ampliar, desenvolver e fortalecer a gestão de resíduos no país. Dentre as suas principais publicações está o Panorama dos Resíduos Sólidos no Brasil, que existe desde 2003 e prioriza o mercado de limpeza pública e de reciclagem, sendo a coleta seletiva abordada de modo complementar (ABRELPE, 2012).

A comparação entre as pesquisas foi possível devido a sua proximidade temporal, visto que elas foram conduzidas em épocas coincidentes ${ }^{2}$. Para direcionar a análise e a apresentação dos resultados, foram estabelecidos dois conjuntos de critérios de avaliação:

\footnotetext{
${ }^{2}$ SNIS, CEMPRE e ABRELPE realizaram suas pesquisas em 2012 e o IBGE, em 2011. Essa combinação foi a mais adequada ao estudo, dada a periodicidade variada na produção dos relatórios, o delay existente entre a sua realização e a publicação efetiva dos dados e o fato de o IBGE não ter lançado edições posteriores da PNSB. Além disso, as versões seguintes dos relatórios possuem características similares às dos ora considerados, mantendo-se, assim, a validade das análises e recomendações.
} 
o primeiro, sobre o conteúdo temático, foi definido de acordo com IPEA (2012a) e inclui a existência e a cobertura da coleta seletiva, as modalidades oferecidas, a quantidade recolhida, o custo dos programas e a participação de cooperativas e catadores; o segundo, sobre os procedimentos metodológicos, foi baseado em Guimarães \& Cabral (1997) e compreende a amostra, o método amostral, a representatividade obtida, a fonte de informações, o instrumento de pesquisa, a forma de coleta e os testes estatísticos. Os dados analisados derivam, principalmente, dos arquivos que cada instituição disponibilizou. Além disso, quando da necessidade de esclarecimento de dúvidas pontuais, houve o contato direto (via telefone e/ou e-mail) com os responsáveis pelas pesquisas.

\section{Resultados}

Os resultados estão divididos em duas partes: na primeira são apresentados os dados sobre a abrangência e a oferta da coleta seletiva, que permitem esboçar um panorama preliminar da situação desse serviço no país (ver Tabela 1); na segunda, as pesquisas são comparadas em termos metodológicos, o que facilita o entendimento das abordagens utilizadas e das diferenças encontradas.

A primeira - e talvez a principal - informação sobre a situação da coleta seletiva no país é uma das que apresentaram maior contraste entre as pesquisas: de acordo com o CEMPRE (2012), 14\% dos municípios brasileiros possuem programas de coleta seletiva; segundo o SNIS (Brasil, 2014) eles são 20\%; para o IBGE (2012), 32\%; e para a ABRELPE (2012), 60\% das cidades brasileiras oferecem o serviço. Uma análise unificada das respostas indicou que, na hipótese mais otimista, o serviço estaria presente em 2.283 cidades $\left(41 \%\right.$ do total) ${ }^{3}$. Apesar de representar "o melhor dos casos", esse número é ainda bastante inferior à cobertura da coleta regular, que chega a quase $98 \%$ dos municípios (IBGE, 2010).

Em relação à localização, uma análise conjunta dos relatórios revelou que a coleta seletiva é mais comum em grandes centros urbanos e em algumas regiões do país. Considerando as faixas de população,

\footnotetext{
${ }^{3} \mathrm{O}$ número foi obtido com base nas respostas originais disponibilizadas, somando-se todos os municípios que afirmaram possuir a coleta seletiva em pelo menos uma das pesquisas.
}

observa-se que $97 \%$ dos municípios com mais de 500 mil habitantes e $82 \%$ dos que possuem entre 100 e 500 mil afirmaram possuir coleta seletiva. Esse número chega a $61 \%$ nos municípios que têm entre 50 e 100 mil habitantes e diminui para $37 \%$ nos com até 50 mil. Entre as regiões, os programas de coleta seletiva predominam no Sul e no Sudeste que têm, respectivamente, $66 \%$ e $54 \%$ dos seus municípios com alguma iniciativa de coleta seletiva, percentuais que chegam a $30 \%$ no Centro-Oeste e $20 \%$ no Norte e no Nordeste (CEMPRE, 2012; Brasil, 2014; IBGE, 2012; ABRELPE, 2012). Mais do que isso, Sul e Sudeste possuem $74 \%$ de todos os municípios com coleta seletiva, embora abriguem $51 \%$ dos municípios brasileiros e produzam $61 \%$ de todo o lixo gerado (Brasil, 2014).

Outra maneira de se avaliar a abrangência da coleta seletiva é em termos populacionais. Não obstante, deve-se diferenciar a população total dos municípios que possuem coleta seletiva da população efetivamente beneficiada pelo serviço. Isso porque, em muitas cidades, a coleta seletiva só é oferecida em áreas urbanas ou em bairros selecionados e, por isso, a mensuração da população atendida depende da cobertura geográfica e territorial de cada programa. Os dados do IBGE (2012) indicam que pouco mais de 53 milhões de pessoas ( $28 \%$ do total) seriam atendidas pela coleta seletiva ${ }^{4}$. O SNIS (Brasil, 2014) apurou um número um pouco menor, de 42 milhões de brasileiros (22\%), mas ainda superior aos 27 milhões (14\%) apresentados pelo CEMPRE (2012). Em qualquer um dos casos, entretanto, a cobertura é novamente bastante inferior à obtida com a coleta regular, que chega a 180 milhões de habitantes (93\% do total) (Brasil, 2014).

Dentre as modalidades de coleta seletiva, predomina no Brasil a realizada porta a porta, na qual há o recolhimento do resíduo diretamente nos logradouros e vias públicas (Grimberg; Blauth, 1998). Segundo o CEMPRE (2012), 88\% dos municípios oferecem essa modalidade, número parecido com os $86 \%$ apresentados pelo SNIS (Brasil, 2014). Essa presença é quase o dobro da obtida pelos Pontos de Entrega Voluntária (PEVs), que estariam presentes em 53\% das cidades

\footnotetext{
${ }^{4}$ Dos 1.796 municípios que afirmaram ao IBGE possuir coleta "Em Atividade", 612 (34\%) disseram que ela está presente em todo o território municipal e 823 (46\%) que ela está em toda a área urbana. Para se chegar ao valor de 53 milhões, somaram-se as respectivas populações rural e urbana desses municípios.
} 
Tabela 1 - Panorama da Coleta Seletiva no Brasil

\begin{tabular}{|c|c|c|c|c|c|}
\hline \multirow[b]{2}{*}{ INDICADOR } & \multicolumn{4}{|c|}{ PESQUISA } & \multirow{2}{*}{$\begin{array}{l}\text { Valor } \\
\text { total|(a) }\end{array}$} \\
\hline & IBGE (2012) & $\begin{array}{l}\text { SNIS (Brasil, } \\
2014 \text { ) }\end{array}$ & CEMPRE (2012) & ABRELPE (2012) & \\
\hline \multicolumn{6}{|l|}{ Abrangência da Coleta Seletiva (CS) } \\
\hline \multirow[t]{2}{*}{ Municípios com CS (valor total e relativo) } & 1.796 & 1.111 & 766 & 3.326 & 5.570 \\
\hline & $32 \%$ & $20 \%$ & $14 \%$ & $60 \%$ & $100 \%$ \\
\hline \multirow[t]{2}{*}{ População dos municíios com CS(b) } & 114.173 .986 & 104.008 .542 & 106.270 .022 & 87.732 .259 (c) & 193.976 .530 \\
\hline & $59 \%$ & $54 \%$ & $55 \%$ & $45 \%$ & $100 \%$ \\
\hline \multicolumn{6}{|c|}{ \% de municipios com CS (por número de habitantes) } \\
\hline Acima de 500 mil & $79 \%$ & $87 \%$ & $92 \%$ & $93 \%$ & 38 \\
\hline Entre 100 e 500 mil & $66 \%$ & $56 \%$ & $66 \%$ & $87 \%$ & 250 \\
\hline Entre 50 e 100 mil & $48 \%$ & $34 \%$ & $35 \%$ & $67 \%$ & 327 \\
\hline Até 50 mil & $29 \%$ & $17 \%$ & $9 \%$ & $58 \%$ & 4.955 \\
\hline \multicolumn{6}{|c|}{ \% de municípios com CS (por região geográfica) } \\
\hline Centro-Oeste & $24 \%$ & $10 \%$ & $4 \%$ & $32 \%$ & 467 \\
\hline Nordeste & $15 \%$ & $5 \%$ & $4 \%$ & $38 \%$ & 1.794 \\
\hline Norte & $14 \%$ & $6 \%$ & $3 \%$ & $47 \%$ & 450 \\
\hline Sudeste & $42 \%$ & $30 \%$ & $24 \%$ & $80 \%$ & 1.668 \\
\hline Sul & $56 \%$ & $38 \%$ & $22 \%$ & $79 \%$ & 1.191 \\
\hline População & & & & & Média \\
\hline População efetivamente atendida pela CS & 53.585 .747 & 42.170 .446 & 27.000 .000 & - & 40.918 .731 \\
\hline (relativa ao total da população) & $28 \%$ & $22 \%$ & $14 \%$ & - & $21 \%$ \\
\hline \multicolumn{6}{|l|}{ Modalidades (\% de municípios) } \\
\hline Com CS porta a porta & - & $86 \%$ & $88 \%$ & $\cdot$ & $87 \%$ \\
\hline Com CS por PEVs & - & $39 \%$ & $53 \%$ & - & $46 \%$ \\
\hline \multicolumn{6}{|l|}{ Cooperativas e catadores } \\
\hline \% de munićpios com cooperativas atuantes & $48 \%$ & $49 \%$ & $65 \%$ & $\cdot$ & $55 \%$ \\
\hline Total de cooperativas & $1.175^{(d)}$ & 757 & $862^{(e)}$ & - & 931 \\
\hline Catadores associados & $30.390^{(d)}$ & 23.408 & - & - & 26.899 \\
\hline \multicolumn{6}{|l|}{ Quantidade recolhida (kg/hab/ano) } \\
\hline Coleta seletiva & - & 11,3 & 13,6 & - & 12,5 \\
\hline Coleta regular & $353^{(d)}$ & 365 & - & 349 & 356 \\
\hline Composição gravimétrica(t) & & (g) & (h) & (i) & \\
\hline Papel/papelão & $\cdot$ & $48 \%$ & $60 \%$ & $41 \%$ & $50 \%$ \\
\hline Plástico & - & $27 \%$ & $19 \%$ & $42 \%$ & $29 \%$ \\
\hline Metais & $\cdot$ & $14 \%$ & $9 \%$ & $9 \%$ & $11 \%$ \\
\hline Vidro & - & $11 \%$ & $11 \%$ & $8 \%$ & $10 \%$ \\
\hline \multicolumn{6}{|l|}{ Custo (RS/tonelada) } \\
\hline Coleta seletiva & $\cdot$ & - & 424 & - & 424 \\
\hline Coleta regular & - & 107 & 95 & 144 & 115 \\
\hline
\end{tabular}

(a) Quantidade total e real de cada categoria e não o somatório da linha. Utilizado como base para o cálculo do percentual. Por exemplo, na primeira linha, 0 total de municípios brasileiros é de 5.570 e o valor de $32 \%$ ( $2^{a}$ coluna) refere-se a 1.796 municípios desses 5.570 Torna-se a média a partir do item População (1 $15^{0}$ linha); (b) Calculada pelos autores com base em IBGE (2013); (c) Valor real, baseado nos municípios efetivamente pesquisados e não na quantidade projetada pela instituição; (d) Dados de IBGE (2010); (e) Dado disponível no site institucional do CEMPRE; () Excluídos o rejeito, a matéria orgânica e outros itens (e.g., madeira, palha, couro, pneus, têxteis etc.); (9) Resíduos destinados à recidlagem; (h) Resíduos da coleta seletiva; (i) Resíduos da coleta regular. Fonte: Elaborado pelos autores a partir dos dados disponíveis em IBGE (2012), SNIS (Brasil, 2014), CEMPRE (2012) e ABRELPE (2012). 
para o CEMPRE (2012) e 39\% delas para o SNIS (Brasil, 2014).

Na modalidade porta a porta, destaca-se o trabalho das cooperativas e associações de catadores. O IBGE (2012) indicou que 48\% dos municípios com coleta seletiva possuem alguma parceria (formal ou informal) com cooperativas ou associações. O SNIS (Brasil, 2014) aponta percentual parecido, de 49\%. 0 resultado encontrado pelo CEMPRE (2012) foi um pouco maior e revelou que elas são agentes executoras da coleta seletiva em $65 \%$ dos municípios. Esses valores sugerem que as cooperativas participam da coleta seletiva em, pelo menos, $55 \%$ dos municípios que prestam o serviço. Ainda assim, o dado pode estar subestimado, pois, de acordo com o próprio IBGE (2012), em cerca de $20 \%$ dos municípios onde não há programas de coleta seletiva funcionando as prefeituras afirmam ter conhecimento da atuação de cooperativas.

0 volume de resíduos recolhido pelas cooperativas, pela prefeitura ou pelos outros agentes executores também foi mensurado, embora de forma muito menos precisa. Com respostas consistentes de 650 municípios (21\% dos respondentes), o SNIS (Brasil, 2014) apurou uma média de 11,3 quilos per capita (kg/cap) recolhidos seletivamente em 2012. Dados do CEMPRE (2012) permitiram estimar, para o mesmo ano, $13,6 \mathrm{~kg} / \mathrm{cap}$. Uma média entre os dois relatórios indica que, em 2012, coletou-se de forma seletiva um volume de $12,5 \mathrm{~kg} / \mathrm{cap}$, o que é praticamente igual ao que já havia sido coletado em 2008, calculado em $12,3 \mathrm{~kg} / \mathrm{cap}$ (IBGE, 2010). Além de demonstrar que a coleta seletiva avançou menos do que se esperava, o volume representa uma pequena parcela (10\%) de todo o material potencialmente reciclável que é gerado e descartado (Brasil, 2014).

Cada tipo de resíduo separado e recolhido seletivamente deve ser direcionado ao tratamento mais adequado. Como recicláveis secos e matéria orgânica têm destinos e preços distintos, a composição gravimétrica torna-se uma informação relevante na análise da coleta seletiva. Nesse indicador houve maior dificuldade de compatibilização dos dados, pois as instituições usaram bases diferentes: o SNIS (Brasil, 2014) contabilizou os resíduos enviados à reciclagem; o CEMPRE (2012) mensurou aqueles coletados seletivamente; e a ABRELPE (2012), os coletados de modo regular. Conjuntamente, eles mostram que, no Brasil, a matéria orgânica representa mais de 50\% do total de resíduos domiciliares. Considerando somente os recicláveis secos, quase $80 \%$ do material recolhido (e não gerado) são compostos de papel, papelão e plástico.

Por fim, deve-se considerar o custo dos programas de coleta seletiva. Dos quatro relatórios, só o CEMPRE (2012) trouxe dados sobre os custos, e de forma bastante limitada. Ele obteve respostas consistentes de pouco menos de 200 municípios e encontrou um custo médio de $\mathrm{R} \$ 424$ por tonelada recolhida, ainda muito superior aos $\mathrm{R} \$ 115 /$ ton da coleta regular (Brasil, 2014; CEMPRE, 2012; ABRELPE, 2012). 0 IPEA (2010) lembra que o acompanhamento financeiro é uma tarefa complexa, e as estimativas dependem tanto das modalidades adotadas quanto do apoio que as prefeituras proporcionam aos catadores; em locais onde são oferecidos galpões, máquinas, luz etc., o gasto é maior do que quando as cooperativas atuam de forma independente e sem o conhecimento dos órgãos públicos.

\section{Diferenças metodológicas nos relatórios}

A comparação das metodologias dependeu, essencialmente, da qualidade dos dados de cada relatório e da quantidade de arquivos que cada instituição disponibilizou, como planilhas com valores primários, glossários, listas de indicadores e descrição de fórmulas. As principais semelhanças e diferenças metodológicas podem ser visualizadas no Quadro 1.

Todas as instituições optaram pela pesquisa de levantamento, tendo IBGE (2012) e SNIS (Brasil, 2014) escolhido uma abordagem censitária e CEMPRE (2012) e ABRELPE (2012) a amostragem. Mais complexos, os processos amostrais merecem ser explicados, pois influenciaram os resultados. Segundo o responsável pela pesquisa do CEMPRE (2012), a amostragem não teve uma metodologia definida e foi obtida de duas formas: pelo contato proposital com cidades que sabidamente tinham programas de coleta seletiva ou com aquelas com grande geração de resíduos; e pelo envio de questionários para os representantes de qualquer prefeitura que já tivesse anteriormente procurado o CEMPRE para algum serviço, como auxílio técnico ou avaliação setorial. Esse relato sugere que a amostragem foi não probabilística, nas modalidades intencional e por conveniência (Anderson et al., 2007; Guimarães \& Cabral, 1997). A instituição ainda afirmou 
Quadro 1 - Procedimentos metodológicos comparados

\begin{tabular}{|c|c|c|c|c|}
\hline \multirow{2}{*}{ Categoria } & \multicolumn{4}{|c|}{ PESQUISA } \\
\hline & IBGE & SNIS & CEMPRE & ABRELPE \\
\hline Método/Amostragem & Censitário & Censitário & $\begin{array}{l}\text { Intencional e por } \\
\text { conveniência }\end{array}$ & Aleatória estratificada \\
\hline $\begin{array}{l}\text { Amostra }{ }^{(a)} \\
\text { ( } n^{0} \text { de municípios) }\end{array}$ & $5.565^{(b)}$ & 5.570 & 1.200 & 401 \\
\hline Municipios respondentes & $5.564^{(0)}$ & 3.043 & 997 & 401 \\
\hline (relativo ao total) & $100 \%$ & $55 \%$ & $18 \%$ & $7 \%$ \\
\hline (relativo à amostra) & $100 \%$ & $55 \%$ & $83 \%$ & $100 \%$ \\
\hline Fonte de dados & Prefeitura & Prefeitura & Prefeitura & Prefeitura \\
\hline Instrumento de pesquisa & Questionário & Questionário & Questionário & Questionário \\
\hline Número de questões sobre coleta seletiva & 6 & 10 & 8 & 3 \\
\hline Forma de coleta de dados & Presencial & Software on-line & Telefone/E-mail & Não divulgado \\
\hline Procedimentos de análise de dados & Estatística descritiva & $\begin{array}{l}\text { Estatística descritiva, } \\
\text { Extrapolação }\end{array}$ & Estatística descritiva & $\begin{array}{l}\text { Estatística descritiva, } \\
\text { Projeçã̃o }\end{array}$ \\
\hline
\end{tabular}

(a) Como IBGE e SNIS utilizaram uma abordagem censitária, eles não possuem "amostra" propriamente dita. Nos dois casos, entenda-se como "universo"; (b) 0 IBGE não considerou cinco municípios formalmente emancipados em janeiro de 2013 (Mojuí dos Campos - PA, Pescaria Brava - SC, Balneário Rincão - SC, Pinto Bandeira - RS e Paráiso das Águas - MS). Não houve alteração na população porque eles foram desmembrados de outros; ${ }^{\left({ }^{(c)}\right.} 0$ município de Abaré (BA) se recusou a responder a pesquisa do IBGE. Fonte: Elaborado pelos autores a partir dos dados disponíveis em IBGE (2012), SNIS (Brasil, 2014), CEMPRE (2012) e ABRELPE (2012).

que foram realizadas visitas técnicas, mas não de forma sistemática. Como ela apoia o trabalho de cooperativas em todo o país, nas eventuais oportunidades em que uma visita era requerida aproveitava-se para conferir as informações prestadas pelo município.

Em contrapartida, o método amostral adotado pela ABRELPE (2012) foi descrito da seguinte maneira: em primeiro lugar, todos os 5.565 municípios brasileiros foram listados e segmentados por Estado e por faixas de tamanho da população; eles então receberam uma numeração aleatória e foram consultados por ordem (sorteio desses números aleatórios) até fechar a cota previamente estipulada de aproximadamente 400. Quando havia dificuldade de se encontrar o responsável, inexistência da informação ou demora no retorno, o município era descartado e substituído. Assim, entendeu-se que o método amostral caracterizou-se como probabilístico, na modalidade estratificada (Anderson et al., 2007; Guimarães \& Cabral, 1997). Como a ABRELPE não permitiu o acesso a informações mais detalhadas, não se pôde conferir a adequação dos cálculos amostrais.
As pesquisas assemelharam-se quanto às fontes de informações, que foram as prefeituras ou seus setores responsáveis pela gestão de resíduos. 0 instrumento de coleta foi o mesmo - o questionário - alterando-se a forma de aplicação. Os pesquisadores do IBGE realizaram contatos presenciais com respondentes previamente identificados; o SNIS disponibilizou um aplicativo on-line, avisando a prefeitura no início do processo e novamente a contatando para a correção ou inclusão de algum dado inconsistente ou faltante; o CEMPRE obteve as respostas por telefone e e-mail; a ABRELPE não foi clara quanto ao procedimento exato adotado (presencial, e-mail, telefone ou outro).

Os questionários diferiram no tamanho, mas as respostas foram analisadas de modo semelhante. O IBGE (2012) sugeriu seis perguntas e os resultados são baseados em estatísticas descritivas, como distribuição de frequências absolutas e relativas (medidas de formato) e média aritmética (medida de posição) (Anderson et al., 2007). 0 SNIS (Brasil, 2014) propôs 10 questões, cujas respostas foram utilizadas para calcular outros 10 indicadores. Houve maior cuidado com valores atípicos ou inconsistentes e, além 
de estatísticas descritivas, foram feitas extrapolações simples. Exclusiva para a coleta seletiva, o CEMPRE (2012) explorou oito questões; porém mesmo as estatísticas descritivas foram limitadas, especialmente devido às respostas incompletas fornecidas pelos municípios. A ABRELPE (2012) abordou a coleta seletiva de modo indireto com três perguntas, mas os resultados basearam-se em procedimentos mais complexos como análises de correlação, regressão e projeções. De acordo com a consultoria que desenvolveu o levantamento, a projeção específica para a coleta seletiva foi realizada da seguinte forma: a) comparação da resposta dos municípios que afirmaram ter coleta seletiva com o que havia sido informado na pesquisa do ano anterior; b) identificação de inconsistências; c) consulta a outras fontes (SNIS e sites dos municípios) para conferir essas inconsistências; e d) análise de evolução com teste de significância através do qui-quadrado. Esses esclarecimentos ajudaram no entendimento da metodologia, mas como as respostas originais e a lista dos municípios utilizados para as projeções não foram divulgados pela ABRELPE, não foi possível refazer ou verificar os cálculos.

\section{Análise e discussão}

Os dados apresentados nos relatórios proporcionam um panorama preliminar da presença e da oferta da coleta seletiva no país. No entanto, como observado, existem valores com grande discrepância, alguns dos quais podem ser explicados (ou contextualizados) pelas escolhas metodológicas realizadas.

A principal divergência entre os relatórios está relacionada à abrangência da coleta seletiva. Lembramos que eles apresentaram percentuais de $14,20,32$ e 60 para o mesmo indicador, qual seja a quantidade de municípios com programas de coleta seletiva. Essa disparidade pode ser explicada pela análise conjunta de três fatores: o método amostral adotado, os procedimentos escolhidos para o cálculo dos resultados e a linguagem utilizada nos questionários. Inicialmente, observa-se que IBGE (2012) e ABRELPE (2012) conseguiram a resposta de toda a amostra visada e SNIS (Brasil, 2014) e CEMPRE (2012) obtiveram 55\% e 83\%, respectivamente. Com a resposta de todas as cidades, o IBGE pôde calcular a abrangência da coleta seletiva de modo simples, dividindo a quantidade dos municípios que afirmaram possuir o serviço pelo total de municípios brasileiros. Mesmo sem terem alcançado a mesma participação, SNIS e CEMPRE realizaram o mesmo tipo de cálculo, tornando seus resultados subestimados. 0 percentual obtido revela somente uma parte daquelas cidades que efetivamente possuem coleta seletiva, já que várias outras acabaram não integrando o conjunto dos respondentes. Nesses casos, quando não se tem a resposta de toda a população, talvez fosse mais indicado fazer cálculos projetivos, como realizado pela ABRELPE (2012).

Vale observar que a taxa de resposta do IBGE (2012) é maior porque a instituição é beneficiada pela lei 5.534 (Brasil, 1968, art. 1ํㅡ), que indica que "[...] toda pessoa natural ou jurídica de direito público ou de direito privado [...] é obrigada a prestar as informações solicitadas pela Fundação IBGE”. Uma alternativa para as outras instituições aumentarem a taxa de resposta é aperfeiçoar a coleta de dados. Pela escala nacional dos estudos, o questionário parece sim ser o instrumento mais adequado, mas quanto à aplicação, versões on-line permitiriam ampliar o número de respondentes sem grandes incrementos nos custos. Uma opção ainda mais avançada seria uma espécie de pré-preenchimento, exigindo que os municípios confirmassem informações básicas (e.g., dados cadastrais) e atualizassem o que fosse necessário (quantidades, volumes etc.).

0 terceiro motivo que ajuda a explicar a diferença nos dados refere-se à forma como a pergunta foi realizada. Como visto, apesar de apresentar coerência entre o cálculo da amostra e o procedimento de análise, o valor de 60\% projetado pela ABRELPE (2012) é bem superior aos percentuais encontrados pelas outras pesquisas (14\%, 20\% e 32\%). Isso não se deve simplesmente a possíveis incorreções nos complexos cálculos projetivos, as quais poderiam originar resultados bastante controversos. Observou-se que, para descrever a situação da coleta seletiva, ABRELPE (2012), SNIS (Brasil, 2014) e CEMPRE (2012) deram como opções de resposta apenas o "sim" (i.e., existe) e o "não". Já o IBGE (2012) ofereceu as alternativas: programa "Em atividade", "Projeto piloto", projeto "Em elaboração", programa "Interrompido" ou "Não há programa". Assim, os 32\% encontrados pelo IBGE (2012) referem-se somente aos municípios que já tinham programas funcionando de maneira completa, ou seja, "Em atividade". Contudo, se eles fossem considerados em conjunto com os municípios que possuíam 
"Projeto piloto" ou projeto "Em elaboração", o total encontrado seria de $55 \%$, algo bem mais próximo dos $60 \%$ apontados pela ABRELPE (2012) (ver Figura 2). Como os programas de coleta seletiva normalmente começam como projetos piloto em determinados bairros e demoram a ser implementados de forma completa em cada município, alternativas pouco elaboradas como "sim" e "não" falham em revelar de maneira precisa a realidade do serviço. Não é de se estranhar, por exemplo, que ao receber uma dessas pesquisas, o respondente de um município que só tenha a coleta seletiva em alguns pontos opte pela resposta "sim", descrevendo de forma incompleta, mas verídica, a situação do serviço na sua localidade.

$\mathrm{O}$ acesso aos dados originais permitiu verificar a coerência das informações prestadas pelos municípios quanto à abrangência da coleta seletiva. As respostas dadas à pesquisa do IBGE (utilizada como base por ter obtido o retorno de todos os municípios brasileiros) foram confrontadas com aquelas fornecidas às outras pesquisas. Duas situações revelaram as divergências maiores: na primeira, $20 \%$ dos municípios que demostraram ao IBGE (2012) ter programas "Em atividade" responderam "não" (isto é, não possuem coleta seletiva) aos outros levantamentos dos quais participaram; na segunda, 7\% dos que declararam ao IBGE (2012) que "Não há programa" deram a resposta "sim" aos outros relatórios, em clara contradição (Tabela 2).
Essa análise não pôde ser feita com a mesma clareza com as opções "Projeto piloto", "Em elaboração" ou programa "Interrompido", que podem representar tanto um "sim" quanto um "não", dependendo da visão de quem responde. Além disso, faz-se a ressalva de que a pesquisa do IBGE foi realizada um ano antes das outras e que a situação da coleta seletiva no município pode realmente ter mudado nesse período com o (re) início do programa ou mesmo com a sua interrupção. Todavia, descobriu-se que, independentemente da resposta dada ao IBGE (2012), 252 municípios afirmaram possuir coleta seletiva a uma instituição ao mesmo tempo em que afirmaram não possuir à outra, resposta visivelmente incoerente. Quando questionado sobre as razões que explicariam essa incongruência, o responsável pela pesquisa do CEMPRE esclareceu que o contato que cada instituição tem na prefeitura nem sempre é o mesmo, e as respostas fornecidas dependem do conhecimento do informante sobre a gestão municipal de resíduos.

Os dados revelaram também que a coleta seletiva não é bem distribuída no território brasileiro, concentrando-se nos grandes centros urbanos e nas regiões Sul e Sudeste, que possuem os dois maiores PIB do país (IBGE, 2016). Moutinho (2013) explica que a probabilidade de existência da coleta seletiva é maior em locais com renda domiciliar e PIB per capita mais altos. Com mais recursos, centros urbanos tornam-se grandes consumidores

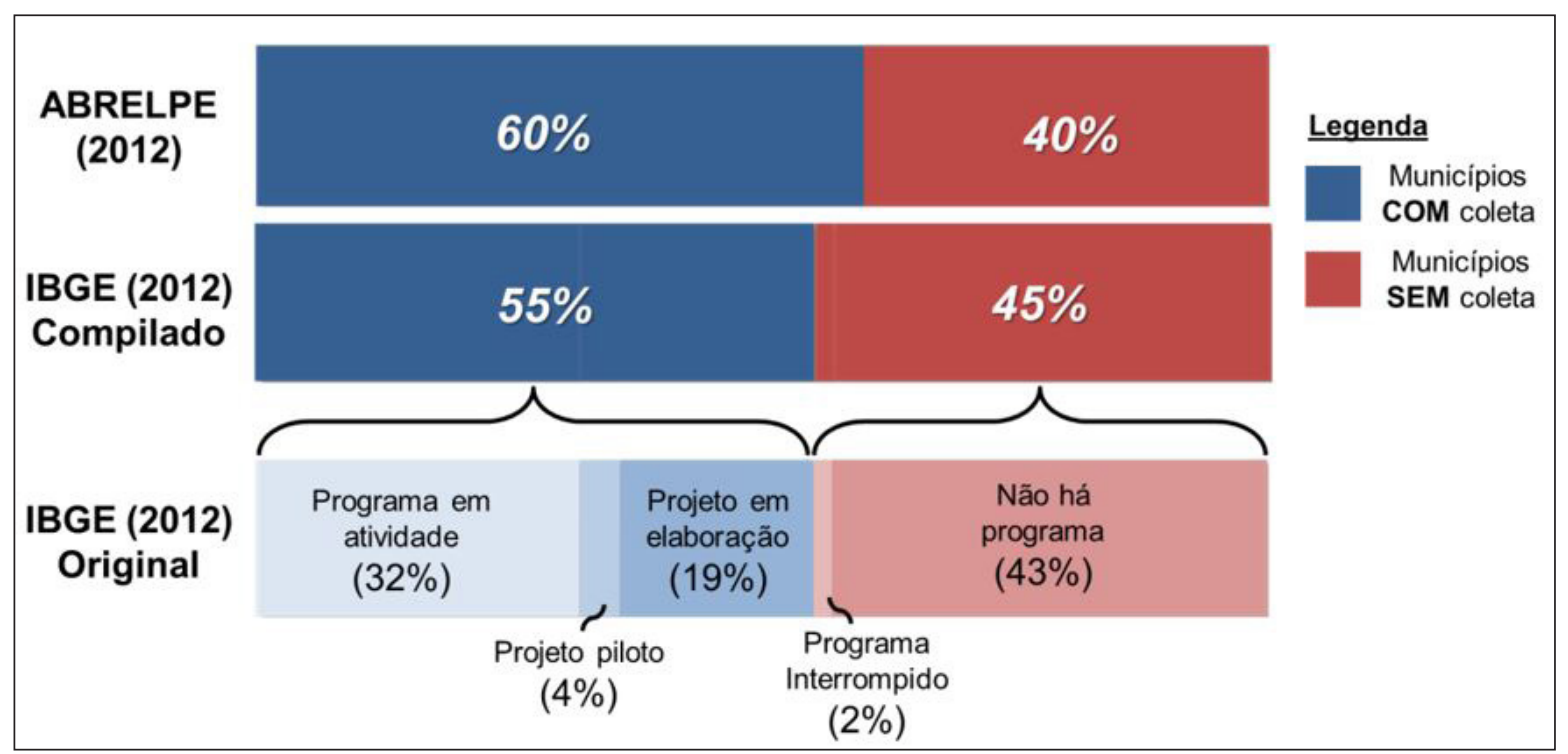

Figura 2 - Comparação dos resultados sobre a abrangência da Coleta Seletiva Fonte: Elaborado pelos autores a partir dos dados disponíveis em IBGE (2012) e ABRELPE (2012). 
Tabela 2 - Comparacãão das respostas dos municípios nas diferentes pesquisas

\begin{tabular}{|c|c|c|c|c|}
\hline \multicolumn{2}{|c|}{ Resposta dada ao IBGE (2012) } & \multicolumn{3}{|c|}{ Resposta dada aos outros relatórios } \\
\hline Situação da coleta seletiva & $\begin{array}{c}\text { Quantidade de } \\
\text { municípios }\end{array}$ & SIM a todos & NÃO a todos & $\begin{array}{c}\text { SIM em um e NÃ0 em } \\
\text { outro }\end{array}$ \\
\hline Programa em atividade & 1.796 & 887 & 359 & 119 \\
\hline Projeto em elaboração & 1.070 & 115 & 475 & 62 \\
\hline Projeto piloto & 184 & 53 & 64 & 14 \\
\hline Programa interrompido & 138 & 25 & 68 & 10 \\
\hline Não há programa & 2.376 & 160 & 924 & 47 \\
\hline Não pesquisado/Recusa & 6 & 1 & 2 & 0 \\
\hline TOTAL & 5.570 & 1.241 & 1.892 & 252 \\
\hline
\end{tabular}

Fonte: Elaborado pelos autores a partir dos dados disponíveis em IBGE (2012), SNIS (Brasil, 2014), CEMPRE (2012) e ABRELPE (2012).

de bens e geradores de resíduos, possuindo ainda maior capacidade de realizar um controle estatístico apurado da coleta seletiva. Por isso há uma tentativa deliberada de incluir os grandes municípios nas amostras por parte das instituições, o que pode ser comprovado pelos números disponíveis. Como visto, a diferença na quantidade de municípios pesquisados (100\%, 55\%, 18\% e 7\% do total) é bem maior do que a diferença na população atendida pela coleta seletiva (59\%, 54\%, 55\% e 45\% do total), conforme apontado por IBGE (2012), SNIS (Brasil, 2014), CEMPRE (2012) e ABRELPE (2012), respectivamente. Ou seja, em termos populacionais, as discrepâncias são menores, tanto porque os $5 \%$ maiores municípios brasileiros concentram $55 \%$ da população total como pelo esforço de as instituições incluirem tais municípios no grupo de respondentes.

Outro fator metodológico percebido foi a utilização, em todas as pesquisas, da mesma fonte de informação: as prefeituras. Logicamente, elas não são as únicas instituições que participam do processo, que é influenciado pela atividade de outros grupos, como cooperativas e associações de catadores, Organizações Não Governamentais (ONGs), associações de bairros, empresas de coleta, organizações que disponibilizam PEVs e mesmo da população. Mais do que isso, o IBAM (2001) lembra que a coleta seletiva conta com a participação de muitos catadores informais. Esse fato é confirmado pelo IPEA (2012b), que estimou que existem no Brasil entre 400 e 600 mil catadores, dos quais apenas $10 \%$ estariam cooperados ou associados. Além dos catadores, existem comerciantes autônomos (sucateiros) que tampouco possuem qualquer tipo de registro, mas são bastante atuantes no mercado de coleta e reciclagem.

Por isso, dada a diversidade de participantes, sugere-se incluir nas pesquisas os outros grupos formalizados que participam do processo e a vertente informal e independente da coleta seletiva, de modo a evitar que os dados sejam apresentados por fonte única, as prefeituras ${ }^{5}$. Como essas participam ativamente dos programas de coleta seletiva e têm interesse no seu sucesso, a autodeclaração - a percepção sobre o próprio desempenho - pode influenciar a confiabilidade dos dados. Ainda, tê-las como as únicas informantes implica em aceitar integralmente as respostas fornecidas. A preocupação não se restringe a possíveis inverdades relatadas, mas ao fato de os valores ficarem sujeitos a um controle estatístico inadequado ou ao conhecimento não especializado das pessoas que foram designadas para responder os questionários, gerando aproximações, palpites ou afirmações convenientes, como evidenciado nos dados da Tabela 2.

Outros problemas observados em todas as pesquisas referem-se à falta de perguntas essenciais sobre a coleta seletiva e a dificuldade na compatibilização de alguns indicadores (como a gravimetria), que só puderam ser comparados com ressalvas ou adaptações. Em outras

\footnotetext{
${ }^{5}$ Na PNSB 2008 (não analisada), o IBGE disse que, além das prefeituras, participaram da pesquisa companhias de saneamento, fundações, consórcios intermunicipais e as associações comunitárias; no entanto, não divulgou quem e quantos foram os entrevistados.
} 
palavras, o tipo e a forma como o dado foi investigado alteraram a capacidade explicativa das pesquisas. Isso poderia ser resolvido com categorias de análise e unidades de medida mais claras, pois a definição de critérios de avaliação - já amplamente desenvolvidos em manuais, guias ou trabalhos científicos sobre a coleta seletiva (cf. IPEA, 2012a; Grimberg \& Blauth, 1998), poderia fundamentar e dar confiabilidade aos questionários. Dentre as questões complementares que proporcionariam uma descrição mais completa da coleta seletiva estão a quantidade de PEVs disponíveis, a taxa de rejeito na triagem, o montante de resíduos aterrados, as reclamações realizadas pela população, a existência de legislação pertinente, os investimentos em educação ambiental etc.

Por fim, uma das informações fundamentais para o monitoramento adequado de um serviço público - o custo - foi uma das mais negligenciadas nos relatórios. As dificuldades de se estimar os valores não justificam que essa informação central tenha sido abordada somente por uma das instituições e de modo precário e inconsistente. A recomendação é para que essa pergunta seja incluída em todos os questionários, preferencialmente acompanhada de outra sobre os benefícios da coleta seletiva (e.g., empregos gerados, aumento da renda, recursos naturais economizados), tendo em vista que o conhecimento dos retornos positivos é um dos incentivos para que comportamentos ambientalmente corretos sejam ampliados e aderidos pela população (Lehman \& Geller, 2004).

Além das considerações gerais já apresentadas, de forma mais específica, todas as pesquisas analisadas podem ser aperfeiçoadas. Aproveitando sua capacidade de obter respostas de todos os municípios e retratar de forma razoavelmente precisa a realidade brasileira, o IBGE deveria produzir estudos mais frequentes sobre a coleta seletiva, já que não existe periodicidade definida para relatórios sobre o tema. A qualidade das perguntas parece adequada, mas o número de questões deve ser ampliado, incentivando os municípios a divulgarem não somente informações qualitativas, mas também dados objetivos e numéricos, como a quantidade recolhida ou a composição gravimétrica dos resíduos.

O relatório do SNIS (Brasil, 2014) é o que mais se destaca na transparência, trazendo muitos arquivos com dados primários. As explicações são detalhadas, permitindo que todos os cálculos sejam refeitos. Sugere-se, no entanto, que eles considerem cálculos projetivos também para a coleta seletiva, pelo fato de não terem atingido a totalidade da amostra e por estarem aptos a realizar tais cálculos.

Um dos maiores desafios do CEMPRE é a divulgação. Os resultados obtidos na CICLOSOFT foram parcialmente disponibilizados no site institucional e os textos explicativos são semelhantes aos de edições anteriores da pesquisa. Não houve o mesmo cuidado presente em outras das suas publicações, como o Guia da Coleta Seletiva ou o CEMPRE Review, ambas muito bem produzidas e apresentadas. A amostra pequena, segundo o responsável pela pesquisa, deve-se à infraestrutura e aos recursos financeiros e humanos insuficientes para se alcançar o número ideal de respondentes. Os pontos positivos concentram-se em ser a única exclusiva para a coleta seletiva e de ter indagado a questão dos custos, tornando-se referência nesse quesito.

Os trabalhos da ABRELPE são, na verdade, focados no mercado de limpeza pública e o fato de abordarem a coleta seletiva acaba enriquecendo suas pesquisas. No caso analisado, ressalta-se a coerência metodológica, pois ela projetou valores para todo o grupo baseada em uma amostra estratificada. Como esses procedimentos estatísticos são mais avançados, seria apropriado que a ABRELPE permitisse o acesso aos dados primários, trazendo maior transparência aos resultados. Uma das dúvidas remanescentes, por exemplo, refere-se ao processo de amostragem que, pelo relato fornecido, deixa a impressão que os respondentes são muito parecidos em todas as edições e que a amostra não seria aleatória, como argumentado. Vale ressaltar que as boas práticas de pesquisa postulam que "[...] os dados devem, após a publicação de seus resultados, ser colocados à disposição dos colegas que desejem replicar o estudo ou desenvolver projetos a partir de seus resultados" (ABC, 2013, p. 7). A instituição explicou que devido ao acordo realizado com os municípios, a maioria das respostas era sigilosa, algo que talvez deva ser revisto, já que são informações sobre a situação de um serviço que, por natureza, é público.

\section{Considerações finais}

As pesquisas analisadas revelaram pelo menos duas grandes questões sobre a coleta seletiva no país: a primeira é que, apesar da sua importância como geradora de emprego, renda e na preservação 
dos recursos naturais, ela é ainda incipiente, estando presente em somente $41 \%$ dos municípios. Ademais, o Brasil ainda desperdiça muito material que poderia ser transformado e reinserido na cadeia produtiva. Em 2012, por exemplo, menos de 1\% da matéria orgânica gerada foi enviada a unidades de compostagem (ABRELPE, 2012; Brasil, 2014). Em relação aos recicláveis secos, foram coletados de forma seletiva apenas $10 \%$ do total de resíduos potencialmente recicláveis (Brasil, 2014). Se todo esse montante que é indevidamente encaminhado aos aterros e lixões fosse reciclado, isso poderia gerar benefícios de quase $\mathrm{R} \$ 8$ bilhões anuais, bem superiores aos valores que atualmente figuram entre $R \$ 1,4$ e $R$ \$ 3,3 bilhões (IPEA, 2010).

Outro ponto percebido é que as pesquisas não são satisfatórias e apresentam somente uma descrição preliminar da situação da coleta seletiva. 0 crescimento desses programas exige que os métodos de investigação sejam cada vez mais aperfeiçoados, já que há consenso que um dos principais problemas no gerenciamento de resíduos sólidos é a falta de dados, informações, controles e comunicação, normalmente insuficientes, dispersos, desconexos e heterogêneos (IPEA, 2012a; Pearce \& Turner, 1993; Brown \& Farrelly, 2009). A dinâmica dispersa da atividade de catação e a falta de infraestrutura (e.g., balanças de pesagem) deixam o controle da coleta seletiva precário e não rotineiro (Brasil, 2014). Mesmo assim, tem-se a impressão que ela não dispõe do acompanhamento exercido na coleta regular e na limpeza urbana, que recebem maior cuidado tanto dos órgãos públicos quanto das empresas que fazem o recolhimento.

As recomendações aqui descritas ainda podem ser incorporadas pelo SINIR (Sistema Nacional de Informações Sobre a Gestão de Resíduos Sólidos), projeto concebido na Política Nacional de Resíduos Sólidos e cuja finalidade é coletar e compartilhar estatísticas sobre as metas e impactos dos programas nacionais, estaduais e municipais de resíduos sólidos. A melhoria na produção, sistematização e disseminação dos dados pode estimular um acompanhamento mais atento das prefeituras, das cooperativas, das organizações interessadas e da sociedade, visto que a indisponibilidade de dados (ou sua baixa qualidade) prejudica uma compreensão mais abrangente da coleta seletiva e impede que políticas públicas e ações conjuntas sejam realizadas com foco e dimensões adequados.

\section{Referências}

Associação Brasileira de Ciências - ABC. (2013). Rigor e integridade na condução da pesquisa científica. Rio de Janeiro: ABC. Recuperado em 6 de setembro de 2016, de www.abc.org.br

Associação Brasileira de Empresas de Limpeza Pública e Resíduos Especiais - ABRELPE. (2012). Panorama dos resíduos sólidos no Brasil 2012. São Paulo: ABRELPE.

Anderson, D. R., Sweeney, D. J., \& Williams, T. A. (2007). Estatística aplicada à administração e economia. São Paulo: CENGAGE Learning.

Brasil. (1968, 14 de novembro). Lei $n^{\circ}$ 5.534, sobre a Prestação de Informações Estatísticas. Brasília: Diário Oficial da União. Recuperado em 25 de agosto de 2016, de www.planalto.gov.br

Brasil.(1985). Reciclagem dos resíduos urbanos, agropecuários, industriais e minerários. Brasília: MIC/CDI.

Brasil. (2010, 2 de agosto). Lei no 12.305, institui a Política Nacional de Resíduos Sólidos. Brasília: Diário Oficial da União. Recuperado em 16 de maio de 2016, de www. planalto.gov.br

Brasil. (2012). O que o brasileiro pensa do meio ambiente e do consumo sustentável. Brasília: MMA. Recuperado em 22 de agosto de 2016, de www.mma.gov.br

Brasil. Sistema Nacional de Informações sobre Saneamento - SNIS. (2014). Diagnóstico do manejo de resíduos sólidos urbanos 2012. Brasília: Ministério das Cidades / SNSA.

Brown, R. R., \& Farrelly, M. A. (2009). Delivering sustainable urban water management: a review of the hurdles we face. Water Science and Technology, 59(5), 839-846. PMid:19273882. http://dx.doi.org/10.2166/wst.2009.028.

Compromisso Empresarial para Reciclagem - CEMPRE. (2010). Lixo urbano: manual de gerenciamento integrado. São Paulo: CEMPRE.

Compromisso Empresarial para Reciclagem - CEMPRE. (2012). Pesquisa Ciclosoft 2012. São Paulo: CEMPRE. Recuperado em 18 de maio de 2016, de www.cempre.org.br

Grimberg, E., \& Blauth, P. (1998). Coleta seletiva de lixo: reciclando materiais, reciclando valores. Polis, 31, 1-100.

Guimarães, R., \& Cabral, J. (1997). Estatística. Portugal: McGraw Hill.

Instituto Brasileiro de Administração Municipal - IBAM. (2001). Manual: gerenciamento integrado de resíduos sólidos. Rio de Janeiro: IBAM/SEDU-PR. 
Instituto Brasileiro de Geografia e Estatística - IBGE. (2010). Pesquisa Nacional de Saneamento Básico 2008. Rio de Janeiro: IBGE.

Instituto Brasileiro de Geografia e Estatística - IBGE. (2012). Perfil dos municípios brasileiros 2011. Rio de Janeiro: IBGE.

Instituto Brasileiro de Geografia e Estatística - IBGE. (2013). Estimativas de população para 1ํo de julho de 2012. Recuperado em 25 de junho de 2016, de www.ibge.gov.br Instituto Brasileiro de Geografia e Estatística - IBGE. (2014). Site institucional. Rio de Janeiro: IBGE. Recuperado em 13 de março de 2016, de www.ibge.gov.br

Instituto Brasileiro de Geografia e Estatística - IBGE. (2016). Contas regionais do Brasil 2012. Rio de Janeiro: IBGE. Recuperado em 25 de outubro de 2016, de www. ibge.gov.br

Instituto de Pesquisa Econômica Aplicada - IPEA. (2010). Pesquisa sobre pagamento por serviços ambientais urbanos para a gestão dos resíduos sólidos. Brasília: IPEA.

Instituto de Pesquisa Econômica Aplicada - IPEA. (2012a). Diagnóstico dos instrumentos econômicos e sistemas de informação para gestão de resíduos sólidos. Brasília: IPEA.

Instituto de Pesquisa Econômica Aplicada - IPEA. (2012b). Diagnóstico sobre catadores de resíduos sólidos. Brasília: IPEA.

International Organization for Standardization - ISO. (1999). ISO 14021: environmental labels and declarations. Genebra: ISO.
Kaliampakos, D., \& Benardos, A. (2013). Underground solutions for urban waste management. Austria: International Solid Waste Association. Recuperado em 17 de fevereiro de 2017, de www.iswa.org

King, A. M., Burgess, S. C., Ijomah, W., \& McMahon, C. A. (2006). Reducing waste: repair, recondition, remanufacture or recycle? Sustainable Development, 14(4), 257-267. http://dx.doi.org/10.1002/sd.271.

Lehman, P. K., \& Geller, E. S. (2004). Behavior analysis and environmental protection: accomplishments and potential for more. Behavior and Social Issues, 13(1), 13-32. http:// dx.doi.org/10.5210/bsi.v13i1.33.

Moutinho, C.S. (2013). Determinantes da coleta seletiva nos municípios brasileiros (Dissertação de mestrado). Escola Nacional de Ciências Estatísticas, Instituto Brasileiro de Geografia e Estatística, Rio de Janeiro.

Pearce, D. W., \& Turner, R. K. (1993). Market-based approaches to solid waste management. Resources, Conservation and Recycling, 8(1-2), 63-90. http://dx.doi. org/10.1016/0921-3449(93)90020-G.

Penteado, M. (2011). Guia pedagógico do lixo. São Paulo: SMA/CEA.

Tchobanoglous, G., \& Kreith, F. (2002). Handbook of solid waste management. New York: McGraw-Hill.

Recebido: Nov. 24, 2016

Aprovado: Maio 22, 2017 